\title{
THE COUPLING RELATIONSHIP BETWEEN TROPICAL UPPER SEA TEMPERATURE FIELD AND EAST ASIAN SUMMER MONSOON
}

\author{
LI, X. ${ }^{1}-$ TU, S. $^{2, *}-$ KANG, $X .^{1}-$ HUANG, $X .^{2}$ \\ ${ }^{1}$ Civil Aviation Flight University of China, 618307 Guanghan, China \\ ${ }^{2}$ Faculty of Information Technology, Beijing University of Technology, 100124 Beijing, China \\ *Corresponding author \\ e-mail:sstu@bjut.edu.cn
}

(Received $3^{\text {rd }}$ Aug 2018; accepted $28^{\text {th }}$ Sep 2018)

\begin{abstract}
In order to study the variability of the upper sea temperature in the tropical Pacific and Indian Oceans and reveal their coupling relationship with East Asian summer monsoon circulation, the singular value decomposition is employed to reveal the variation of $120 \mathrm{~m}$ sea temperature in the tropical Pacific and Indian Oceans, the main modalities of anomalous activities of the East Asian summer monsoon, and their mutual relation. The results show that during the summer of years with strong summer monsoon, the western Pacific subtropical high is weak and its location is northerly. In years with strong summer monsoon, the sinking movement of vertical velocity anomalies in East Asia weakens the Meiyu front and vice versa. When the $850 \mathrm{hPa}$ east trade winds in the equatorial central and eastern Pacific Ocean are enhanced, the middle Indian Ocean and the western Pacific Ocean show westerly anomalies. Meanwhile, if the meridional wind anomalies on both sides of the equator in the central Indian Ocean/ eastern Pacific and East Asia show a clear convergent and divergent pattern, respectively, the corresponding $120 \mathrm{~m}$ sea temperature shows a La Niña state and is easy to trigger the strong East Asian summer monsoon.
\end{abstract}

Keywords: singular value decomposition, $850 \mathrm{hPa}$ wind filed, the tropical Pacific, El Niño state, $120 \mathrm{~m}$ sea temperature

\section{Introduction}

Located in the East Asian monsoon region, China shows a typical monsoon climate. The monsoon in China shows large interannual variability leading to frequent droughts and floods (Hao et al., 2016). Therefore, it is of great practical significance to study the variability and main impacting factors of East Asian summer monsoon (EASM). The strength of the EASM is closely related to the subtropical high, the atmospheric circulation in tropics and mid-high latitudes, and the thermal effects of the Tibetan Plateau (Duan et al., 2008; Li et al., 2016). The anomaly of sea temperature is the most important for the prediction of EASM among the above factors (Zhang and Li, 2004). It impacts the precipitation in the monsoon region by impacting the monsoon circulation (Zhang et al., 1999). In the tropical oceans, the El Niño-Southern Oscillation (ENSO) is a strong signal of air-sea interactions. Studies have shown that the ENSO has an important impact on the EASM as well as the climate of China. The warming period of El Niño affects the strength and the burst time of the EASM, thereby affecting the amount of summer precipitation in East Asia (Feng et al., 2011; Zhou et al., 2012; Zhang et al., 2017). Many studies about the variability of the EASM have been conducted based on the sea surface temperature (SST). However, the subsurface sea temperature is less affected by the sea-air interface and has more significant interannual variation compared to the SST, thus, it has a large impact on the continued development of the climate. Chen et al. $(2011,2012)$ studied the interannual and interdecadal 
variability of subsurface ocean temperature anomalies in the tropical Pacific and their impacts on the climate anomalies in China using the variation of sea temperature in the thermocline. They found that the subsurface sea temperature affects the variation of EASM by affecting the subtropical high and the trough-ridge system in mid-high latitudes. Recent studies also show that there is a mutual interaction between the subsurface sea temperature anomalies in the western Pacific warm pool and the ENSO cycle (Li and Li, 2014; Shan et al., 2016; Li et al., 2017).

The above studying areas are mostly in the tropical Pacific Ocean, which cannot reveal the characteristic that the cold and warm center from the tropical Eastern Indian Ocean to the western Pacific Ocean is an integral system (Cai et al., 2005). The direct relationship between the EASM circulation field and the tropical subsurface sea temperature field is also rarely discussed. Therefore, the aim of this study is to reveal the general pattern of forecasting the EASM and the ENSO. Considering the areas from the tropical Indian Ocean to the Pacific Ocean, a singular value decomposition (SVD) method is employed to study the variation of tropical subsurface sea temperature and the EASM and discuss the coupling relationship between them.

\section{Data and method}

The data used in this study is the monthly anomalies of global upper sea temperature (1955-2003) produced by Scripps/NODC Joint Environmental Data Analysis Center (JEDAC) and downloaded from the Nanjing Atmospheric Data Service Center. It is a $5^{\circ}$ $\times 2^{\circ}$ dataset covering $60^{\circ} \mathrm{S}-60^{\circ} \mathrm{N}$ with 11 vertical layers at depths of $0,20,40,60,80$, $120,160,200,240,300$, and $400 \mathrm{~m}$. The data from $30^{\circ} \mathrm{S}-40^{\circ} \mathrm{N}$ in the Indo-Pacific region is selected for this study. The $2.5^{\circ} \times 2.5^{\circ} 850 \mathrm{hPa}$ monthly mean data from the National Centers for Environmental Prediction/ National Center for Atmospheric Research (NCEP/NCAR) reanalysis are also selected.

The methods employed here include the synthetic analysis and the SVD. SVD is a method for analyzing the correlation between two element fields, that is, several pairs of correlative spatial distributions of the two element fields. Such spatial distribution can explain the cross-covariance of the two fields to the greatest extent (John et al., 1992). Its main advantage is that it is universal in the diagnostic analysis of the time-space coupled signals in meteorological fields. It is more effective than the natural orthogonal function and the typical correlation method when analyzing the connection between two different element fields and is a powerful tool to study the spatiotemporal relationship between two sequences of element fields (Ding and Jiang, 1995).

\section{Circulation characteristics in years with strong/weak EASM}

An Index of EASM (IEASM) defined by Zhang et al. (Zhang et al., 2003) is the difference between the anomalies of $850 \mathrm{hPa}$ zonal wind in East Asian tropical monsoon trough $\left(10^{\circ} \sim 20^{\circ} \mathrm{N}, 100^{\circ} \sim 150^{\circ} \mathrm{E}\right)$ and East Asian subtropical zone $\left(25^{\circ} \sim 35^{\circ} \mathrm{N}\right.$, $\left.100^{\circ} \sim 150^{\circ} \mathrm{E}\right)$ in June, July, and August. That is, IEASM $=\mathrm{U} 850 \mathrm{hPa}\left(10^{\circ} \sim 20^{\circ} \mathrm{N}\right.$, $\left.100^{\circ} \sim 150^{\circ} \mathrm{E}\right)-\mathrm{U} 850 \mathrm{hPa}\left(25^{\circ} \sim 35^{\circ} \mathrm{N}, 100^{\circ} \sim 150^{\circ} \mathrm{E}\right)$. A higher IEASM means a stronger summer monsoon and vice versa. This paper selected the data from 1955 to 1998. After standardizing, the years with the normalized IEASM $>1$ are defined as the years with strong EASM and those with normalized IEASM $<-1$ are defined as the years with weak EASM. The years with strong/weak EASM are calculated by the above method, 
which are listed in Table 1. The rest of years are considered as the years with normal EASM.

Table 1. The years with strong/weak EASM defined by IEASM

\begin{tabular}{c|l|l|l|l|l|l}
\hline Strong/weak & \multicolumn{7}{|c}{ Years } \\
\hline EASM & 1967 & 1972 & 1974 & 1978 & 1981 & 1984 \\
Strong & 1985 & 1986 & 1994 & 1997 & 2001 & 2002 \\
\hline EASM & 1955 & 1956 & 1959 & 1969 & 1980 & 1983 \\
Weak & 1988 & 1995 & 1998 & & & \\
\hline
\end{tabular}

In order to understand the variation characteristics of circulation in years with strong/weak EASM, a synthesis analysis is conducted using the years of strong and weak EASM to explore the variation of atmospheric circulation field during the EASM. Figure $1 a$ and $b$ are the summer (July) $850 \mathrm{hPa}$ anomalous wind field for years with strong and weak EASM, respectively. In Figure 1a, the western Pacific subtropical high in the northern hemisphere (corresponding to the cyclonic circulation anomaly) is weaker than normal and its location is more northerly with the axis at $25^{\circ} \mathrm{N}$. The Australia high in the southern hemisphere (corresponding to the anti-cyclonic circulation anomaly) is also weaker than normal, but its weakening intensity is far less than that of the western Pacific subtropical high. This corresponds to an air pressure anomaly field which has high and low values in the south and north, respectively, which forms a strong southeast and southwest anomalous airflow across the equator strengthening the EASM circulation. At $45^{\circ} \mathrm{E}$, the northward Somalia jet across the equator further strengthens the EASM circulation. Therefore, the easterly airflow from the south side of the western Pacific subtropical high, the cross-equatorial southerly airflow from $105^{\circ} \sim 120^{\circ} \mathrm{E}$ in the southern hemisphere, and the westerly airflow from the Indian Ocean come together and form the southeasterly and southwesterly airflows. The southeasterly airflow is a subtropical monsoon airflow while the southwesterly airflow is a tropical monsoon airflow, both providing the warm and wet southerly airflow for East Asian monsoon zone. East Asia to the east of $100^{\circ} \mathrm{E}$, the Korean peninsula, and Japan are all affected by these airflows, and they are also the main water vapor source for the summer precipitation in Eastern China. When this northward warm wet airflow meets the cold air from the circulation of mid-high latitude, a type of subtropical monsoon called Meiyu front is formed (Qin and Wang, 2015). In Figure 1b, the anomaly of the circulation field is almost opposite to that in Figure 1a. The western Pacific subtropical high in the northern hemisphere (corresponding to the anti-cyclonic circulation anomaly) is stronger than normal and is more southerly with the axis at $20^{\circ} \mathrm{N}$, while the Australia high in the southern hemisphere (corresponding to the cyclonic circulation anomaly) is stronger than normal, but its strengthening intensity is far less than that of the western Pacific subtropical high. This corresponds to an air pressure anomaly field with high and low values in the north and south, respectively, which forms a strong northeast and northwest anomalous airflow across the equator weakening the EASM circulation. Therefore, the years with strong and weak EASM have significant differences in the tropospheric low-level circulation field: In the summer of years with strong/weak EASM, the tropical region in East Asia-Pacific shows a closed cyclonic/anti-cyclonic circulation anomaly corresponding to a weaker/stronger western Pacific subtropical high. Gong and He (2002) and Liu and Guo 
(2005) found that the geo-potential height field in East Asia shows negative anomalies during the period when EASM is stronger while the situation is opposite when EASM is weak. Zhang and Wang (2006) and Wu and Zhang (2011) pointed out that the EASM circulation is stronger/weaker when cyclonic/anti-cyclonic circulation anomalies occur in the tropical monsoon region of East Asia, which is in line with the results in this study.
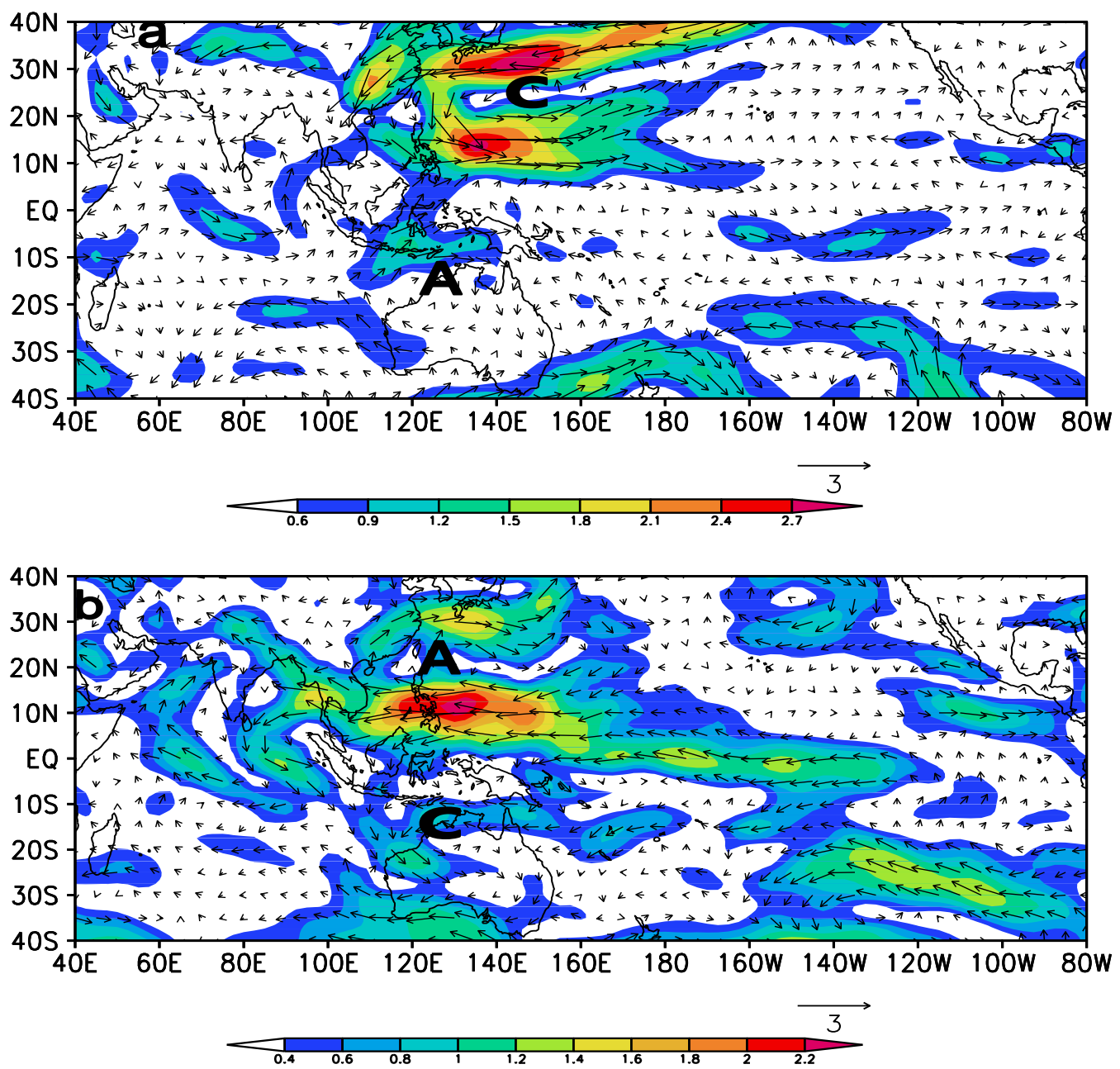

Figure 1. The anomalies of the $850 \mathrm{hPa}$ wind field (unit: $\mathrm{m} / \mathrm{s}$ ) in the summer of years with (a) strong and (b) weak EASM. A: anti-cyclone; $C$ : cyclone

In order to further understand the characteristics of circulation in the East Asian monsoon region during the summer of years with strong and weak EASM. Figure $2 a$ and $b$ show the mean longitude-height profiles of the vertical velocity anomalies in $25^{\circ} \sim 35^{\circ} \mathrm{N}$ in the East Asian monsoon region during the summer of years with strong and weak EASM, respectively. In the years with strong EASM (Fig. 2a), the vertical velocity from the near ground to the upper level in $110^{\circ} \sim 140^{\circ} \mathrm{E}$ shows anomalies of sinking movement, and the upward movement in the summer Meiyu front area $\left(25^{\circ} \sim 35^{\circ} \mathrm{N}, 110^{\circ} \sim 140^{\circ} \mathrm{E}\right)$ is weakened, indicating the weakening of the Meiyu front intensity in East Asia. In the years with weak EASM (Fig. 2b), the vertical velocity from the near ground to the upper level in $110^{\circ} \sim 140^{\circ} \mathrm{E}$ shows anomalies of upward 
movement, and strong upward movement appears in the Meiyu front area $\left(25^{\circ} \sim 35^{\circ} \mathrm{N}\right.$, $110^{\circ} \sim 140^{\circ} \mathrm{E}$ ), leading to the of strengthening of the Meiyu front intensity in East Asia. Thus, the vertical velocity anomalies in East Asia are significantly different in the summers of years with strong and weak EASM. In the years with strong/weak EASM, the vertical velocity anomalies in East Asia are downward/upward, weakening/strengthening the Meiyu front.
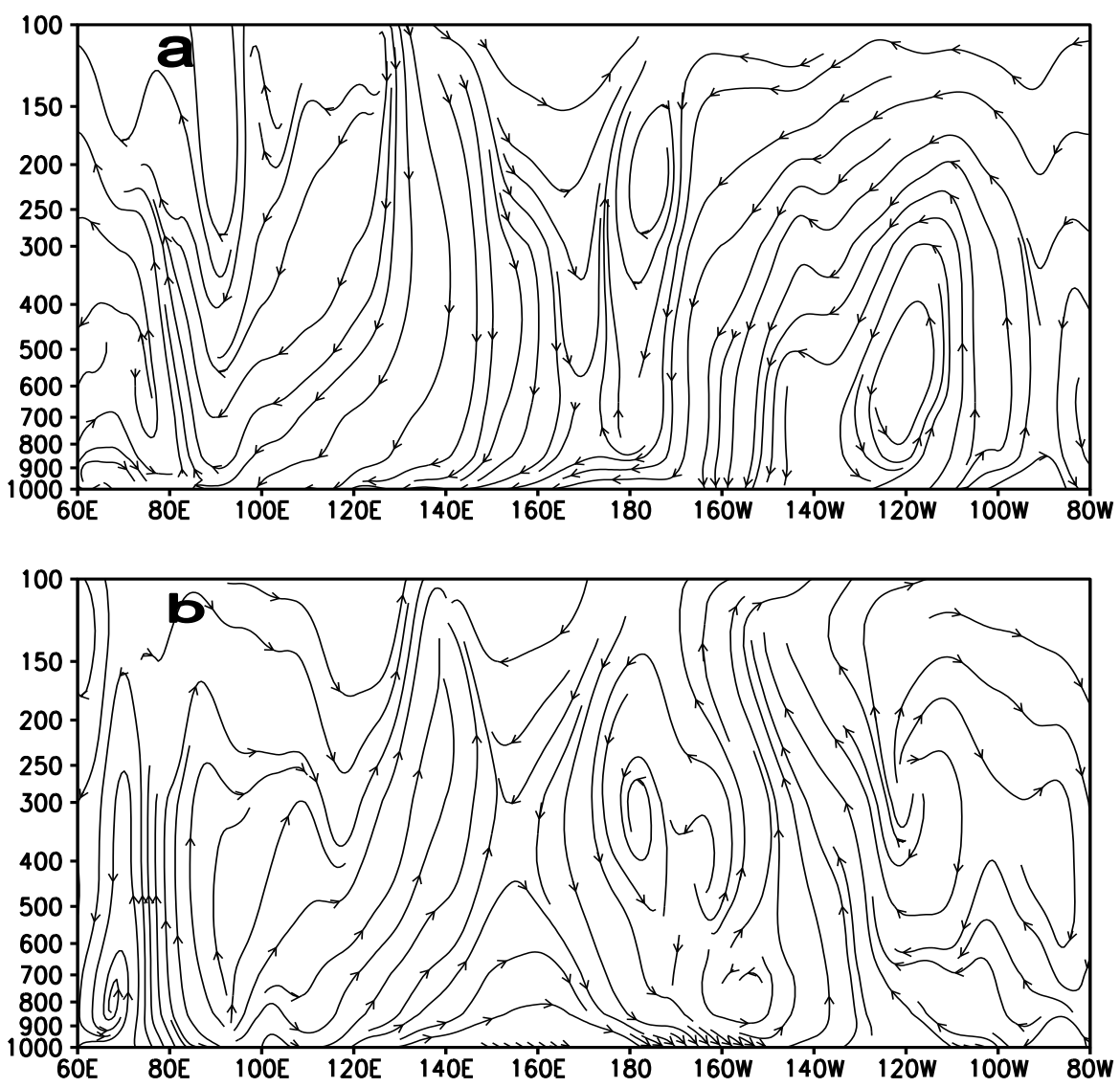

Figure 2. Mean longitude-height profiles of the vertical velocity anomalies in $25 \sim 35^{\circ} \mathrm{N}$ in the East Asian monsoon region during the summer of years with (a) strong and $(b)$ weak EASM

\section{Results}

\section{Coupling relationship between subsurface sea temperature and $850 \mathrm{hPa}$ wind field}

According to $\mathrm{Li}$ et al. (2018), the $120 \mathrm{~m}$ layer in the equatorial region from the central Indian Ocean to the western Pacific Ocean and the $40 \mathrm{~m}$ layer in the equatorial eastern Pacific Ocean have the highest correlation with the IEASM. Since the distributions of the correlation field in the eastern Pacific are roughly the same in the layers of $40 \mathrm{~m}$ and $120 \mathrm{~m}$, the relationship between the $120 \mathrm{~m}$ sea temperature and the summer monsoon reflects the relationship between subsurface sea temperature and the EASM in most regions from the tropical Pacific to the Indian Ocean. Meanwhile, in order to analyzing the Pacific as a whole system without splitting the east and the western Pacific, the $120 \mathrm{~m}$ layer sea temperature in winter (January) is selected to discuss the coupling relation between $120 \mathrm{~m}$ layer sea temperature and the $850 \mathrm{hPa}$ wind field using SVD in order to understand the covariation of the sea temperature field 
and the wind field during the same period. Figure 3 shows the left and right heterogeneous correlation graphs and time coefficients of the first mode of SVD selecting the winter $120 \mathrm{~m}$ normalized sea temperature anomalies as the left field and the normalized $850 \mathrm{hPa}$ zonal wind anomalies as the right field. Table 2 shows the corresponding main information of the first three modes of SVD. It can be seen from Table 2 that the first mode interprets $39.98 \%$ of the total covariance, reflecting the main coupling characteristics between the $120 \mathrm{~m}$ layer sea temperature field and the $850 \mathrm{hPa}$ zonal wind field. For the first three modes, the correlations between time coefficients of the left and the right singular vectors are high and this correlation is significant at 0.001 confidence level. Therefore, a detailed analysis is conducted on the heterogeneous correlation field of the first mode.
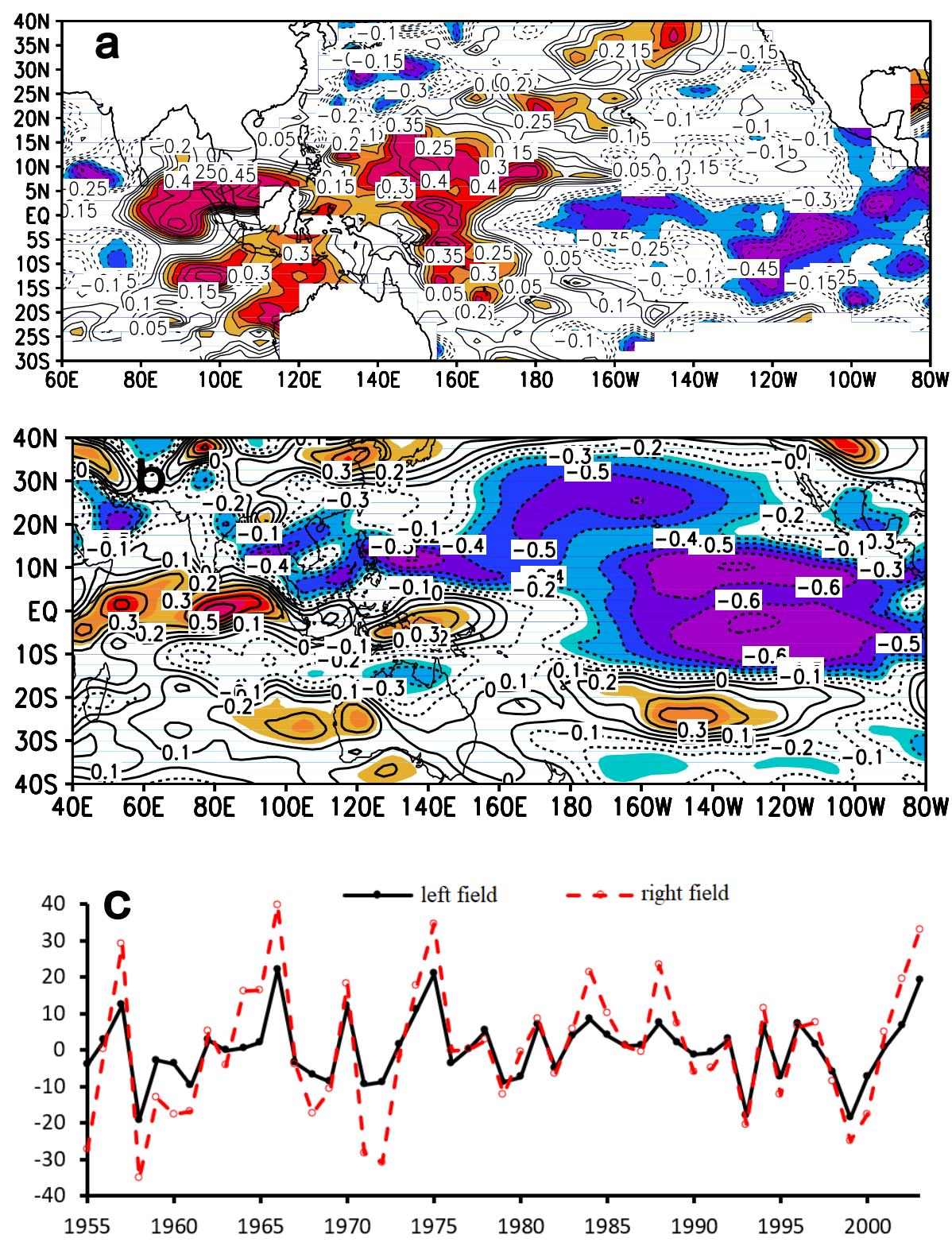

Figure 3. Heterogeneous correlation graphs between winter $120 \mathrm{~m}$ sea temperature field and $850 \mathrm{hPa}$ zonal wind field: (a) left field, (b) right field, and (c) time coefficient. The shadow means the values significant at 0.1 confidence level 
Table 2. Information of the first three modes of SVD between sea temperature field and zonal wind field

\begin{tabular}{c|c|c|c}
\hline $\begin{array}{c}\text { Sequence } \\
\text { number }\end{array}$ & Correlation coefficients & $\begin{array}{c}\text { The sum of squares of the } \\
\text { interprets covariance\% }\end{array}$ & $\begin{array}{c}\text { Accumulation of the sum of } \\
\text { squares of the interprets } \\
\text { covariance\% }\end{array}$ \\
\hline 1 & 0.91 & 39.98 & 39.98 \\
2 & 0.90 & 8.71 & 48.69 \\
3 & 0.92 & 5.59 & 54.28 \\
\hline
\end{tabular}

In Figure $3 a$, the region from the equatorial eastern Indian Ocean to the western Pacific shows positive anomalies of sea temperature, with the center of the positive values located in $10^{\circ} \mathrm{S} \sim 10^{\circ} \mathrm{N}, 80^{\circ} \sim 170^{\circ} \mathrm{E}$. The correlation coefficient in the southern part of the Bay of Bengal, the region from Sumatra to the southern part of the South China Sea, and the equatorial ocean near $160^{\circ} \mathrm{E}$ reach 0.5 (significant at 0.001 confidence level). Most of the equatorial eastern Pacific shows negative anomalies. The absolute value of the maximum correlation coefficient is comparable with the corresponding values from the equatorial eastern Indian Ocean to the western Pacific. The absolute value of the correlation coefficient of the negative anomalies in the equatorial central Indian Ocean is lower. In Figure 3b, the zonal wind in the equatorial central and eastern Pacific shows easterly anomalies and the eastward trade wind is enhanced. Its negative center is located in $10^{\circ} \mathrm{S} \sim 10^{\circ} \mathrm{N}, 150^{\circ} \sim 100^{\circ} \mathrm{W}$ with the maximum correlation coefficient of 0.7 (significant at 0.001 confidence level). The region from the equatorial central Indian Ocean to the western Pacific Ocean shows westerly anomalies indicating the existence of westerly jets (Ke et al., 2015). The positive center of this region is in $5^{\circ} \mathrm{S} \sim 5^{\circ} \mathrm{N}, 50^{\circ} \sim 100^{\circ} \mathrm{E}$ with the maximum correlation coefficient of 0.5 (significant at 0.001 confidence level). As the modal correlation coefficient is positive, the time coefficients of the left and right fields share the same positive and negative phase on average (Fig. 3c). When the time coefficient is strongly positive, the trade wind in the equatorial central and eastern Pacific Ocean is enhanced. The region from center Indian Ocean to the western Pacific Ocean shows westerly anomalies. Meanwhile, the sea temperature in the region from the equatorial eastern Indian Ocean to the western Pacific Ocean becomes higher while the sea temperature in the central Indian Ocean and the eastern Pacific becomes lower, showing a La Niña state. On the contrary, when the time coefficient is strongly negative, the trade wind in the equatorial central and eastern Pacific Ocean is weakened. The region from center Indian Ocean to the western Pacific Ocean shows easterly anomalies. Meanwhile, the sea temperature in the region from the equatorial eastern Indian Ocean to the western Pacific Ocean becomes lower while the sea temperature in the central Indian Ocean and the eastern Pacific becomes higher, showing an El Niño state. Besides, the time coefficients show that the trends of the two fields are in generally consistent and both of them show clear characteristics of interannual variability.

Figure 4 shows the left and right heterogeneous correlation graphs and time coefficients of the first mode of SVD selecting the winter $120 \mathrm{~m}$ normalized sea temperature anomalies as the left field and the normalized $850 \mathrm{hPa}$ meridional wind anomalies as the right field. Table 3 shows the corresponding main information of the first three modes of SVD. It can be seen from Table 3 that the first mode interprets 
$38.45 \%$ of the total covariance, reflecting the main coupling characteristics between the $120 \mathrm{~m}$ layer sea temperature field and the $850 \mathrm{hPa}$ meridional wind field. For the first three modes, the correlations between time coefficients of the left and the right singular vectors are high. Therefore, an analysis is conducted on the heterogeneous correlation field of the first mode. In Figure $4 a$, the equatorial eastern Pacific shows positive anomalies of sea temperature. The center of the positive values located in $10^{\circ} \mathrm{S} \sim 5^{\circ} \mathrm{N}$, $170^{\circ} \sim 110^{\circ} \mathrm{W}$ with the maximum correlation coefficient of 0.4 (significant at 0.01 confidence level) while the correlation coefficients in the region of positive anomalies in the equatorial central Indian Ocean are low. The region from the equatorial eastern Indian Ocean to the western Pacific shows negative anomalies of sea temperature, with the center of the negative values located in $5^{\circ} \sim 15^{\circ} \mathrm{N}, 110^{\circ} \sim 150^{\circ} \mathrm{E}$. The maximum of the correlation coefficient is comparable with that in the equatorial eastern Pacific Ocean. In Figure $4 b$, the meridional wind in the eastern Pacific Ocean to the north of the equator shows northerly anomalies with the maximum correlation coefficient of 0.6 (significant at 0.001 confidence level) while that to the south of the equator shows southerly anomalies. Therefore, the meridional wind anomaly is convergent from both hemispheres to the equatorial eastern Pacific Ocean, which is conducive to the accumulation of the warm water near the equatorial eastern Pacific Ocean. Similarly, the meridional wind in the equatorial central Indian Ocean shows northerly and southerly anomalies to the north and south of the equator, respectively, which is also conducive to the accumulation of the warm water near the central Indian Ocean. East Asia $\left(110^{\circ} \sim 130^{\circ} \mathrm{E}\right)$ shows southerly and northerly anomalies to the north and south of the equator, respectively, which is divergent and is not conducive to the accumulation of the warm water near the equatorial western Pacific Ocean. As the modal correlation coefficient is positive, when the time coefficients of the left and right fields are strongly positive, the meridional wind anomalies on the two sides of the equator are convergent in the central Indian Ocean and eastern Pacific Ocean but divergent in East Asia. In this condition, the sea temperature in the central Indian Ocean and eastern Pacific Ocean increases while the sea temperature in the region from the eastern Indian Ocean to the western Pacific Ocean decreases, showing an El Niño state. On the contrary, when the time coefficients of the left and right fields are strongly negative, the meridional wind anomalies on the two sides of the equator are divergent in the central Indian Ocean and eastern Pacific Ocean but convergent in East Asia. In this condition, the sea temperature in the central Indian Ocean and eastern Pacific Ocean decreases while the sea temperature in the region from the eastern Indian Ocean to the western Pacific Ocean increases, showing a La Niña state. The time coefficients (Fig. 4c) show that the trends of the two fields are in generally consistent and both of them show clear characteristics of interannual variability.

Table 3. Information of the first three modes of SVD between sea temperature field and meridional wind field

\begin{tabular}{c|c|c|c}
\hline $\begin{array}{c}\text { Sequence } \\
\text { number }\end{array}$ & Correlation coefficients & $\begin{array}{c}\text { The sum of squares of the } \\
\text { interprets covariance\% }\end{array}$ & $\begin{array}{c}\text { Accumulation of the sum of } \\
\text { squares of the interprets } \\
\text { covariance\% }\end{array}$ \\
\hline 1 & 0.93 & 38.45 & 38.45 \\
2 & 0.91 & 9.27 & 47.72 \\
3 & 0.91 & 6.92 & 54.64 \\
\hline
\end{tabular}



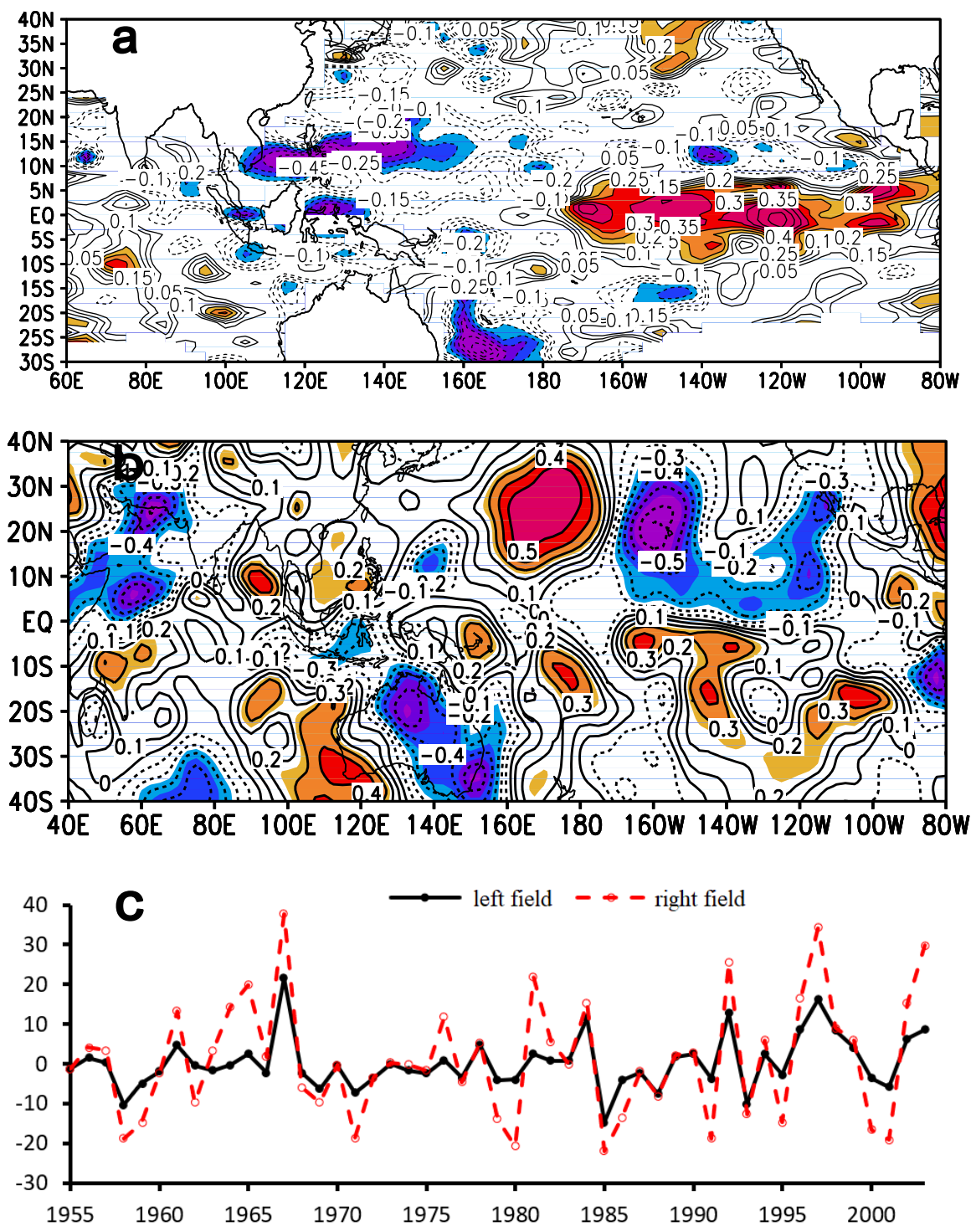

Figure 4. Heterogeneous correlation graphs between winter $120 \mathrm{~m}$ sea temperature field and $850 \mathrm{hPa}$ meridional wind field: (a) left field, (b) right field, and (c) time coefficient. The shadow means the values significant at 0.1 confidence level

\section{Coupling relationship between subsurface sea temperature in tropical Pacific-Indian Ocean and EASM circulation}

The correlation coefficients are calculated between the IEASM and the sea temperature anomalies in the region from the tropical Pacific Ocean to the tropical Indian Ocean. The calculation is conducted month by month and layer by layer from 0 to 400-m depth. It is found that the IEASM has high correlations with the sea temperature anomalies in the equatorial region from the central Indian Ocean to the eastern Pacific Ocean and these correlations change with time. The correlation is the highest when the sea temperature field leads and lags the monsoon for six months and four months, respectively, and the distribution characteristics are significant ( $\mathrm{Li}$ et al., 2018; Guo et al., 2018). It can be seen that the tropical subsurface sea temperature affects the intensity of EASM by affecting the atmospheric circulation in East Asian, 
while the variation of EASM also affects the distribution of the sea temperature field. To further understand the coupling relationship between $120 \mathrm{~m}$ sea temperature field and EASM circulation field, the SVD is conducted between these two fields for the conditions that the sea temperature field leads and lags the EASM circulation field for six months and four months, respectively.

\section{Coupling relationship when subsurface sea temperature field leads wind field}

Figure 5 shows the left and right heterogeneous correlation graphs and time coefficients of the first mode of SVD selecting the winter (January) $120 \mathrm{~m}$ normalized sea temperature anomalies as the left field and the summer (July) normalized $850 \mathrm{hPa}$ wind field anomalies as the right field. Table 4 shows the corresponding main information of the first three modes of SVD. It can be seen from Table 4 that the first mode interprets $37.92 \%$ of the total covariance, reflecting the main coupling characteristics between the $120 \mathrm{~m}$ layer sea temperature field and the $850 \mathrm{hPa}$ wind field. For the first three modes, the correlations between time coefficients of the left and the right singular vectors are high (significant at 0.001 confidence level). Therefore, an analysis is conducted on the heterogeneous correlation field of the first mode.

Table 4. Information of the first three modes of SVD between sea temperature field and wind field

\begin{tabular}{c|c|c|c}
\hline $\begin{array}{c}\text { Sequence } \\
\text { number }\end{array}$ & Correlation coefficients & $\begin{array}{c}\text { The sum of squares of the } \\
\text { interprets covariance \% }\end{array}$ & $\begin{array}{c}\text { Accumulation of the sum of } \\
\text { squares of the interprets } \\
\text { covariance \% }\end{array}$ \\
\hline 1 & 0.92 & 37.92 & 37.92 \\
2 & 0.90 & 10.03 & 47.95 \\
3 & 0.91 & 7.45 & 55.40 \\
\hline
\end{tabular}

In the right field in Figure $5 a$, the region from the equatorial eastern Indian Ocean to the western Pacific shows westerly anomalies. The region locates in $0^{\circ} \sim 15^{\circ} \mathrm{N}$, $70^{\circ} \sim 180^{\circ} \mathrm{E}$, and the highest correlation is found around $80^{\circ} \sim 150^{\circ} \mathrm{E}$ with the maximum correlation coefficient of 0.8 (significant at 0.001 confidence level), which is in line with the latitudinal band and eastward stretch of the westerly jet in summer during the years with strong EASM. Meanwhile, the western Pacific subtropical high in the northern hemisphere (corresponding to the anti-cyclonic circulation anomaly) is weaker than normal, indicating that the EASM circulation is strengthened. In the corresponding left field in Figure $5 b$, the region from the equatorial eastern Indian Ocean to the western Pacific shows positive anomalies of sea temperature centered in $10^{\circ} \mathrm{S} \sim 10^{\circ} \mathrm{N}$, $100^{\circ} \sim 170^{\circ} \mathrm{E}$. The correlation coefficients in the south of the Bay of Bengal and the equatorial ocean near $160^{\circ} \mathrm{E}$ are 0.4 which is significant at 0.01 confidence level. Most regions in the equatorial central Indian Ocean and the equatorial eastern Pacific Ocean show negative anomalies, and the absolute value of the maximum correlation coefficient is lower than that in the region from the equatorial eastern Indian Ocean to the western Pacific. According to Figure 5c, when the time coefficient is strongly positive, the sea temperature in the region from the equatorial eastern Indian Ocean to the western Pacific Ocean becomes higher while the sea temperature in the central Indian Ocean and the eastern Pacific becomes lower in winter, showing a La Niña state. 
As the sea temperature leads the monsoon for six months, the EASM in La Niña years will be stronger than normal. On the contrary, when the time coefficient is strongly negative, the sea temperature in the region from the equatorial eastern Indian Ocean to the western Pacific Ocean becomes lower while the sea temperature in the central Indian Ocean and the eastern Pacific becomes higher in winter, showing an El Niño state and leading to a weaker EASM. Besides, the time coefficients show that the trends of the two fields are in generally consistent and both of them show clear characteristics of interannual variability.
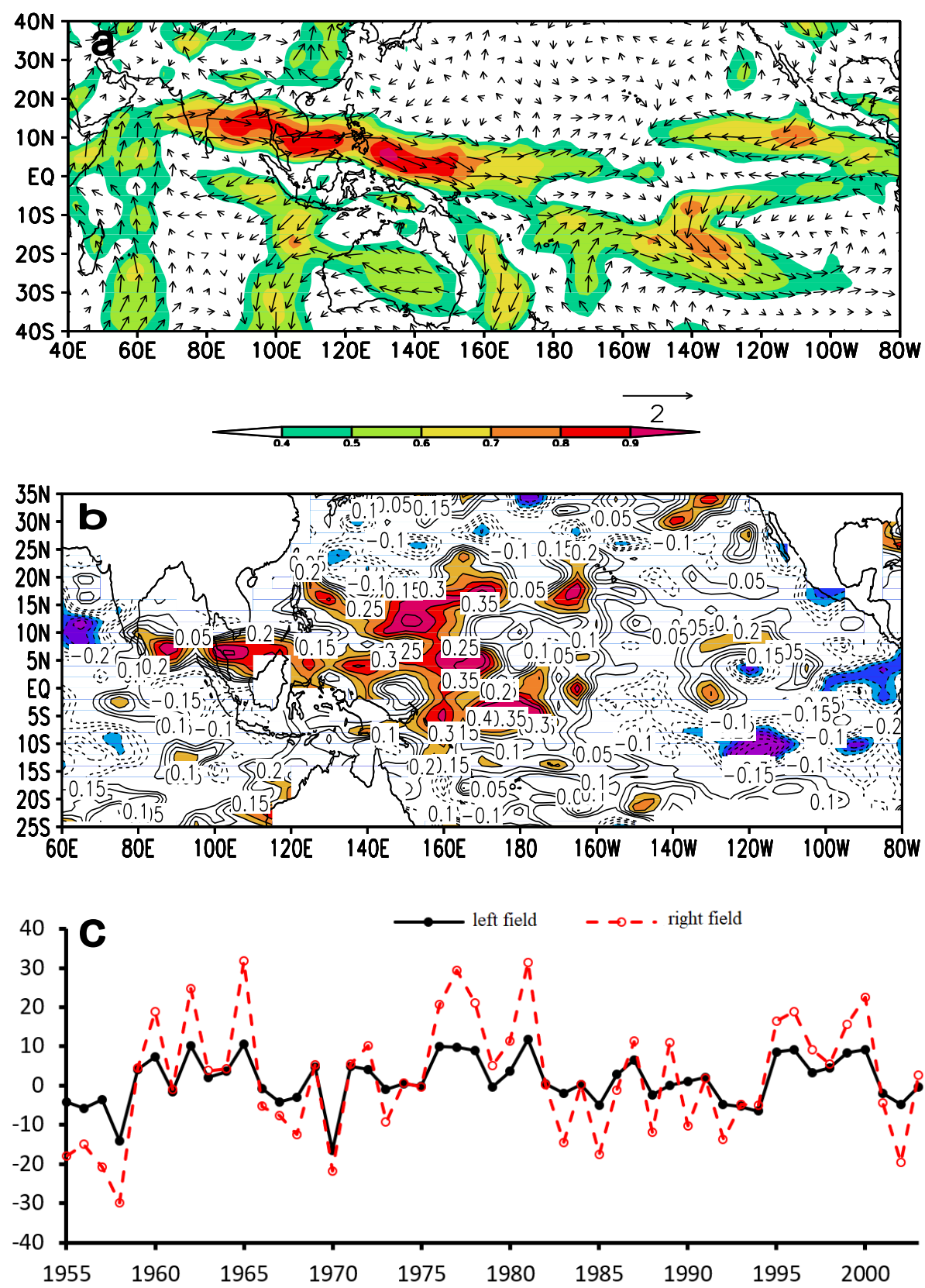

Figure 5. Heterogeneous correlation graphs between $120 \mathrm{~m}$ sea temperature field and $850 \mathrm{hPa}$ meridional wind field when sea temperature leads the wind for six months: (a) left field, (b) right field, and (c) time coefficient. The shadow means the values significant at 0.1 confidence level 


\section{Coupling relationship when subsurface sea temperature field lags wind field}

Figure 6 shows the left and right heterogeneous correlation graphs and time coefficients of the first mode of SVD selecting the winter (November) $120 \mathrm{~m}$ normalized sea temperature anomalies as the left field and the summer (July) normalized $850 \mathrm{hPa}$ wind field anomalies as the right field. Table 5 shows the corresponding main information of the first three modes of SVD. It can be seen from Table 5 that the first mode interprets $40.15 \%$ of the total covariance, reflecting the main coupling characteristics between the $120 \mathrm{~m}$ layer sea temperature field and the $850 \mathrm{hPa}$ wind field. For the first three modes, the correlations between time coefficients of the left and the right singular vectors are high. An analysis is conducted on the heterogeneous correlation field of the first mode. The distribution of the right field in Figure $6 a$ is similar to that in Figure $5 a$, indicating the strengthening of EASM circulation. In the corresponding left field in Figure $6 b$, the equatorial eastern Pacific Ocean shows positive anomalies in sea temperature while the positive anomalies in the equatorial eastern Indian Ocean are relatively low. The highest correlation is found in $5^{\circ} \mathrm{S} \sim 5^{\circ} \mathrm{N}, 160^{\circ} \sim 120^{\circ} \mathrm{W}$ with the maximum correlation coefficient of 0.4 (significant at 0.01 confidence level). The region from the equatorial eastern Indian Ocean to the western Pacific shows negative anomalies, with the absolute value of the maximum correlation coefficient similar to that in the equatorial eastern Pacific Ocean. According to Figure $6 c$, when the time coefficient is strongly positive, the EASM is stronger than normal. As sea temperature lags monsoon for four months, the sea temperature in the region from the equatorial eastern Indian Ocean to the western Pacific Ocean becomes lower while the sea temperature in the central Indian Ocean and the eastern Pacific becomes higher in autumn and winter, showing an El Niño state. On the contrary, when the time coefficient is strongly negative, the EASM is weaker than normal. The sea temperature in the region from the equatorial eastern Indian Ocean to the western Pacific Ocean becomes higher while the sea temperature in the central Indian Ocean and the eastern Pacific becomes lower in autumn and winter, showing a La Niña state. The time coefficients show that the trends of the two fields are also in generally consistent and both of them show clear characteristics of interannual variability.

Table 5. Information of the first three modes of SVD between sea temperature field and wind field

\begin{tabular}{c|c|c|c}
\hline $\begin{array}{c}\text { Sequence } \\
\text { number }\end{array}$ & Correlation coefficients & $\begin{array}{c}\text { the sum of squares of the } \\
\text { interprets covariance \% }\end{array}$ & $\begin{array}{c}\text { Accumulation of the sum of } \\
\text { squares of the interprets } \\
\text { covariance \% }\end{array}$ \\
\hline 1 & 0.90 & 40.15 & 40.15 \\
2 & 0.91 & 12.49 & 52.64 \\
3 & 0.88 & 7.88 & 60.52 \\
\hline
\end{tabular}

\section{Discussion}

The covariation of the sea temperature field and the wind field can be summarized as follow: When the $850 \mathrm{hPa}$ trade wind in the equatorial central and eastern Pacific Ocean increases/decreases, the region from the central Indian Ocean to the western Pacific Ocean shows westerly/easterly anomalies, or the meridional wind anomalies on the two sides of the equator are convergent/divergent in the central Indian Ocean and eastern 
Pacific Ocean but divergent/convergent in East Asia. The corresponding $120 \mathrm{~m}$ sea temperature in the region from the eastern Indian Ocean to the western Pacific Ocean increases/decreases, and the sea temperature in the central Indian Ocean and eastern Pacific Ocean decreases/ increases, showing a La Niña/El Niño state.

From the lead-lag SVD above, it is found that: When the sea temperature in the region from the central Indian Ocean to the western Pacific Ocean is higher/lower than normal and the sea temperature in the central Indian Ocean and the eastern Pacific Ocean is lower/higher than normal, a La Niña/El Niño state will be shown. After that, the EASM is stronger/weaker than normal, and the increase/decrease of EASM circulation leads to an El Niño/La Niña state in the tropical Pacific and Indian oceans in autumn and winter. This result is consistent with (Ke et al., 2015) and (Guo et al., 2018), further verifying the relationship between the subsurface sea temperature and the EASM.
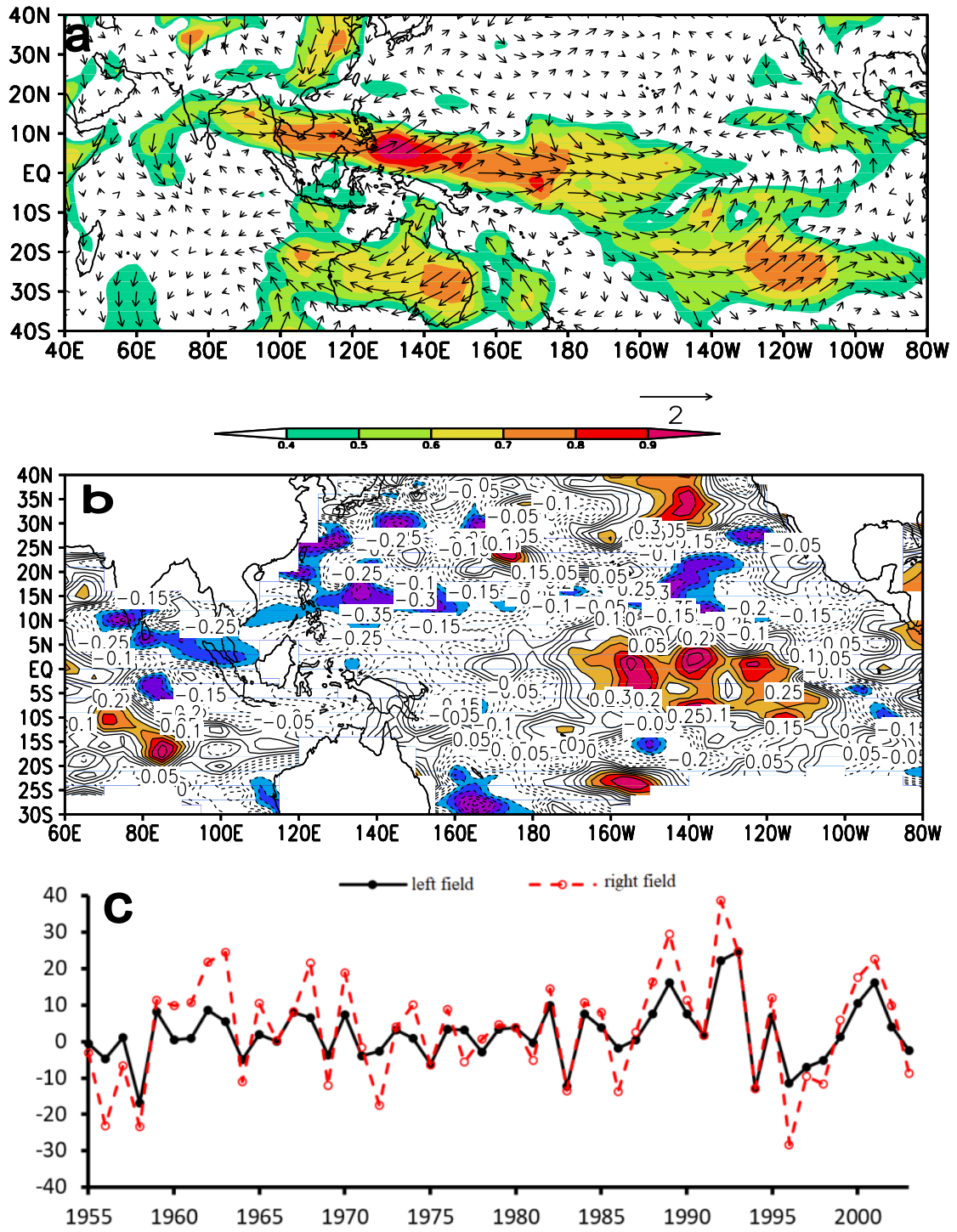

Figure 6. Heterogeneous correlation graphs between winter $120 \mathrm{~m}$ sea temperature field and $850 \mathrm{hPa}$ meridional wind field when sea temperature lags the wind for four months: (a) left field, (b) right field, and (c) time coefficient. The shadow means the values significant at 0.1 confidence level 
In summary, the distribution of tropical subsurface sea temperature anomalies has an impact on the interannual variation of the EASM while the anomalies of EASM change the thermal state of the ocean. There is a mutual interaction between the EASM and the subsurface sea temperature in the tropical region from the Pacific Ocean to the Indian Ocean. The tropical subsurface sea temperature anomalies are an important reference for predicting the variation of EASM. However, this study only focuses on the subsurface sea temperature of the tropical ocean. More parameters which are representative of the ocean characteristics (such as heat capacity and salinity) (Yang et al., 2017) are needed for the future work. Meanwhile, the mechanism of interaction between the EASM and the subsurface sea temperature in the tropical Pacific and Indian Ocean needs to be further explored.

\section{Conclusions}

This study analyzes the interannual variation and circulation characteristics of the IEASM. The characteristics of the subsurface sea temperature anomaly field and the EASM anomaly field in the tropical Indian and Pacific Ocean are investigated, and their coupling relationship is discussed in this study. It turned out that:

The intensity of the EASM has obvious interannual variability. The IEASM defined by Zhang et al. (2003) during the years with strong/weak EASM are analyzed, and the result shows that the tropospheric low-level circulation is significantly different in the years with strong and weak EASM. In the summer years with strong/weak EASM, the western Pacific subtropical high is located more north/south than usual, and the tropical region in East Asia and the Pacific Ocean shows closed cyclonic/anti-cyclonic anomaly circulation, and the western Pacific subtropical high is weak/strong than normal.

The characteristics of the integral circulation in the EASM region during the years with strong and weak EASM show that the vertical velocity anomalies in the EASM region are significantly different during the summer of the year with strong and weak EASM. The vertical velocity anomalies in East Asia are downward/upward during the years with strong and weak EASM leading to a weaker/stronger Meiyu front.

The covariation of the sea temperature field and the wind field is: When the $850 \mathrm{hPa}$ trade wind in the equatorial central and eastern Pacific Ocean increases/decreases, the region from the central Indian Ocean to the western Pacific Ocean shows westerly/easterly anomalies, or the meridional wind anomalies on the two sides of the equator are convergent/divergent in the central Indian Ocean and eastern Pacific Ocean but divergent/convergent in East Asia. The corresponding $120 \mathrm{~m}$ sea temperature in the region from the eastern Indian Ocean to the western Pacific Ocean increases/decreases, and the sea temperature in the central Indian Ocean and eastern Pacific Ocean decreases/ increases, showing a La Niña/El Niño state.

When the winter $120 \mathrm{~m}$ sea temperature in the region from the equatorial eastern Indian Ocean to the western Pacific is higher than normal and that in the central Indian Ocean and the eastern Pacific Ocean is lower than normal, which means the distribution of the sea temperature is a La Niña state, it is easy to be with strong EASM, and the distribution of the sea temperature tends to turn into an El Niño state during the autumn and winter. In contrast, when the winter $120 \mathrm{~m}$ sea temperature in the region from the equatorial eastern Indian Ocean to the western Pacific is lower than normal and the that in the central Indian Ocean and the eastern Pacific Ocean is higher than normal, which means the distribution of the sea temperature is an El Niño state, it is easy to be with 
weak EASM, and the distribution of the sea temperature tends to turn into a La Niña state during the autumn and winter.

Acknowledgements. This work was supported in part by the China Civil Aviation Flight Technology and Flight Safety Research Base Open Fund Project (F2016KF02).

\section{REFERENCES}

[1] Cai, Y., Zhang, J., Yu, W. (2005): An analysis of temperature anomaly in 0-400 m layer of equatorial Indian and Pacific Oceans. - Journal of Tropical Oceanography 24(4): 6066.

[2] Chen, Y., Zhao, Y., Wang, F., et al. (2011): The decadal variability of tropic subsurface ocean temperature anomaly and its impact on climate of China. - Journal of Tropical Meteorology 27(6): 785-796.

[3] Chen, Y., Zhao, Y., Feng, J., et al. (2012): ENSO cycle and climate anomaly in China. Chinese Journal of Oceanology and Limnology 30(6): 985-1000.

[4] Ding, Y., Jiang, Z. (1995): Generality of singular value decomposition in diagnostic analysis of meteorological field. - Acta Meteorologica Sinica 54(3): 365-372.

[5] Duan, A., Wu, G., Liang, X. (2008): Influence of the Tibetan Plateau on the summer climate patterns over Asia in the IAP/LASG SAMIL model. - Advances in Atmospheric Sciences 25(4): 518-528.

[6] Feng, J., Chen, W., Tam, C., et al. (2011): Different impacts of El Nino and El Nino Modoki on China rainfall in the decaying phases. - International Journal of Climatology 31(14): 2091-2101.

[7] Gong, D., He, X. (2002): Interdecadal change in Western Pacific subtropical high and climatic effects. - Acta GeographicaSinica 57(2): 185-193.

[8] Guo, S., Li, F., Ge, F. (2018): A strong correlation between pacific subsurface ocean temperature and East Asian summer monsoon. - Transactions of Atmospheric Sciences 41(1): 103-112.

[9] Hao, L., Ding, Y., Min, J. (2016): Relationship between summer monsoon change in East Asia and abnormal summer rainfall in North China. - Plateau Meteor 35(5): 1280-1289.

[10] John, M., Catherine, S., Christopher, S. (1992): Singular value decomposition of wintertime sea surface temperature and $500 \mathrm{mb}$ height anomalies. - Journal of Climate 5(6): 561-576.

[11] Ke, Z., Hua, L., Zhong, L., et al. (2015): The influence of sea surface temperature anomaly on the East Asian summer monsoon strength and its precursor. - Journal of Applied Meteorological Science 26(5): 536-544.

[12] Li, W., Zhang, R., Sun, C., et al. (2016): Recent research advances on the interannualinterdecadal variations of drought/flood in South China and associated causes. - Journal of Applied Meteorological Science 27(5): 577-591.

[13] Li, X., Li, C. (2014): Occurrence of two types of El Nino events and the subsurface ocean temperature anomalies in the equatorial Pacific. - Chinese Science Bulletin 59(21): 20982107.

[14] Li, X., Xu, F., Chen, H., et al. (2017): Correlation analysis of the cycle process between the Western Pacific warm pool and ENSO during 1980 - 2016. - Journal of Marine Meteorology 37(3): 85-94.

[15] Li, X., Tu, S., Tang, Y., et al. (2018): Correlation analysis of East Asian summer monsoon and subsurface ocean temperature from the Pacific Ocean to the Indian Ocean in the tropics. - Applied Ecology and Environmental Research 16(1): 81-96. 
[16] Liu, Y., Guo, Y. (2005): Impact of pressure system anomaly over mid high latitude on the interdecadal change of East Asia summer monsoon. - Plateau Meteorology 24(2): 129135.

[17] Qin, Y., Wang, P. (2015): Anomalies of the ascending branch structure in the Hadley cell over the Eastern Asia monsoon region and their impacts on the precipitation in the Yangtze River basin in summer. - Journal of Tropical Meteorology 31(4): 467-474.

[18] Shan, C., Li, Y., Ren, R., et al. (2016): Characteristics of the West Pacific warm pool thermal condition and its effects on the ENSO events based on the GODAS data. Journal of the Meteorological Sciences 36(5): 674-680.

[19] Wu, B., Zhang, R. (2011): Interannual variability of the East Asian summer monsoon and its association with the anomalous atmospheric circulation over the mid-high latitudes and external forcing. - Acta Meteorologica Sinica 69(2): 219-233.

[20] Yang, X., Wu, X., Xu, J. (2017): A Review on the upper ocean heat and salt content in the Western Pacific warm pool. - Transactions of Oceanology and Limnology (5): 18-30.

[21] Zhang, Q., Wang, Y. (2006): The response of East Asian monsoon circulation between winter and summer to sea surface temperature over the Pacific Ocean. - Climatic and Environmental Research 11(4): 487-498.

[22] Zhang, Q., Tao, S., Chen, L. (2003): The inter-annual variability of east Asian summer monsoon indices and its association with the pattern of general circulation over East Asia. - Journal of Meteorological Research 61(4): 559-568.

[23] Zhang, R., Li, Q. (2004): Impact of sea temperature variability of tropical oceans on East Asian monsoon. - Meteorological Monthly 30(12): 22-26.

[24] Zhang, R., Sumi, A., Kimoto, M. (1999): A diagnostic study of the impact of El Nino on the precipitation in China. - Adv. Atmos. Sci. 16(2): 229-241.

[25] Zhang, R., Min, Q., Su, J. (2017): Impact of El Nino on atmospheric circulations over East Asia and rainfall in China: Role of the anomalous western North Pacific anticyclone. - Science China: Earth Sciences 47(5): 544-553.

[26] Zhou, W., Chen, W., Wang, D. (2012): The implications of El Nino-Southern Oscillation signal for South China monsoon climate. - Aquatic Ecosystem Health \& Management 15(1): 14-19. 